\title{
Adsorption-induced step formation
}

Thostrup, P.; Christoffersen, Ebbe; Lorensen, Henrik Qvist; Jacobsen, Karsten Wedel; Besenbacher, Flemming; Nørskov, Jens Kehlet

Published in:

Physical Review Letters

Link to article, DOI:

10.1103/PhysRevLett.87.126102

Publication date:

2001

Document Version

Publisher's PDF, also known as Version of record

Link back to DTU Orbit

Citation (APA):

Thostrup, P., Christoffersen, E., Lorensen, H. Q., Jacobsen, K. W., Besenbacher, F., \& Nørskov, J. K. (2001). Adsorption-induced step formation. Physical Review Letters, 87(12), 126102.

https://doi.org/10.1103/PhysRevLett.87.126102

\section{General rights}

Copyright and moral rights for the publications made accessible in the public portal are retained by the authors and/or other copyright owners and it is a condition of accessing publications that users recognise and abide by the legal requirements associated with these rights.

- Users may download and print one copy of any publication from the public portal for the purpose of private study or research.

- You may not further distribute the material or use it for any profit-making activity or commercial gain

- You may freely distribute the URL identifying the publication in the public portal

If you believe that this document breaches copyright please contact us providing details, and we will remove access to the work immediately and investigate your claim. 


\title{
Adsorption-Induced Step Formation
}

\author{
P. Thostrup, ${ }^{1}$ E. Christoffersen, ${ }^{2,3}$ H. T. Lorensen, ${ }^{2}$ K. W. Jacobsen, ${ }^{2}$ F. Besenbacher, ${ }^{1 *}$ and J. K. Nørskov ${ }^{2}$ \\ ${ }^{1}$ CAMP, Institute of Physics and Astronomy, University of Aarhus, DK-8000 Aarhus, Denmark \\ ${ }^{2}$ CAMP, Department of Physics, Technical University of Denmark, DK-2800 Kgs. Lyngby, Denmark \\ ${ }^{3}$ Interdisciplinary Research Center for Catalysis, Technical University of Denmark, DK-2800 Kgs. Lyngby, Denmark
}

(Received 15 March 2001; published 30 August 2001)

\begin{abstract}
Through an interplay between density functional calculations, Monte Carlo simulations and scanning tunneling microscopy experiments, we show that an intermediate coverage of $\mathrm{CO}$ on the $\operatorname{Pt}(110)$ surface gives rise to a new rough equilibrium structure with more than $50 \%$ step atoms. CO is shown to bind so strongly to low-coordinated Pt atoms that it can break Pt-Pt bonds and spontaneously form steps on the surface. It is argued that adsorption-induced step formation may be a general effect, in particular at high gas pressures and temperatures.
\end{abstract}

DOI: $10.1103 /$ PhysRevLett.87.126102

PACS numbers: 68.43.Bc, 68.37.Ef

A crystalline material usually exposes planar facets at low temperatures. The reason for this is that defects on the crystal surface, i.e., steps and kinks, are energetically expensive and therefore infrequent. The defect formation energy is given by the energy required to break the bonds between atoms in the surface layer. For a Pt crystal, for instance, this is of the order $0.25 \mathrm{eV}$ per bond. On such a surface very high temperatures are needed before a sizable fraction of surface Pt-Pt bonds are broken spontaneously [1]. We show in this Letter that, by exposing a $\operatorname{Pt}(110)$ surface to $\mathrm{CO}$, the energy required to break Pt-Pt nearestneighbor (NN) bonds in the surface approaches zero and consequently the equilibrium structure of the surface with $\mathrm{CO}$ adsorbed is one where the surface is microscopically rough with more than $50 \%$ of the atoms associated with steps. We suggest this adsorption-induced microroughening to be a general phenomenon which may control the properties of metal surfaces under high gas pressures.

The system we have chosen to study in detail is $\mathrm{CO} / \mathrm{Pt}(110)$. The equilibrium structure of the clean surface is the missing-row $(1 \times 2)$ reconstruction [2] shown in Fig. 1a. In the [001] direction, perpendicular to the close-packed rows, interactions are weak. High energy steps are associated with the breaking of Pt bonds in the (110) direction, cf. Fig. 1b.

We have studied the CO-induced lifting of the $\mathrm{Pt}(110)$ $(1 \times 2)$ reconstruction by following with scanning tunneling microscopy (STM) the process in real time at room temperature (RT) as well as at elevated temperatures. (For further details see [3].) In Fig. 1b an atomic-scale STM image of the first steps in the structural transformation at RT is shown. It is seen that the process occurs through the breaking of Pt-Pt bonds in the close-packed direction, leading to the creation of "holes" when the CO coverage reaches a critical value of $\theta_{\mathrm{CO}} \approx 0.2$ [4], consistent with previous findings [5-8]. At RT the process is kinetically limited and the thermodynamical equilibrium structure is therefore obtained only at elevated temperatures, $\sim 400 \mathrm{~K}$.

In Fig. 2 we show the observed structures at two different $\mathrm{CO}$ coverages. The first is a structure that forms after saturating the surface with $\mathrm{CO}$ at RT followed by annealing to $400 \mathrm{~K}$. This temperature is high enough to make the surface atoms mobile, as observed when imaging the response of the surface to $\mathrm{CO}$. This means that the system approaches equilibrium, but some of the $\mathrm{CO}$ also desorbs. The absolute coverage after annealing was determined as the ratio between the integrated areas of thermal desorption spectra from the annealed structure and the full coverage $(2 \times 1)-p 2 m g$ phase and was determined to be $\theta_{\mathrm{CO}}=0.8 \pm 0.1$. The second equilibrium structure is the ordered $(2 \times 1)$ - $p 2 m g$-CO phase, obtained by cooling the $\mathrm{Pt}(110)$ crystal from $\sim 600 \mathrm{~K}$ in an ambient pressure of $10^{-7}$ Torr $\mathrm{CO}$. In this structure the metal surface forms a $(1 \times 1)$ structure with $\mathrm{CO}$ adsorbates sitting on top of every Pt atom and nearest-neighbor $\mathrm{CO}$ molecules being tilted $\sim 25^{\circ}$ in opposite directions [6,7]. At coverages lower than 1, the CO molecules are not imaged with STM due to the adsorbate's frustrated motion. For the dense, ordered $(2 \times 1)-p 2 m g$-CO structure with $\theta_{\mathrm{CO}}=1$, the $\mathrm{CO}$ molecules are, however, imaged since they are locked into place by mutual repulsive interactions.

Our STM experiments agree with previous experiments about the structure at saturation $\left(\theta_{\mathrm{CO}}=1\right)$. A very rough structure is, however, observed at an intermediate coverage

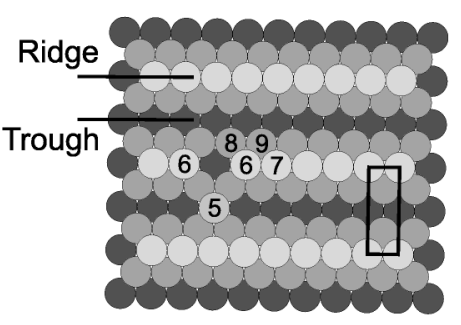

(a)

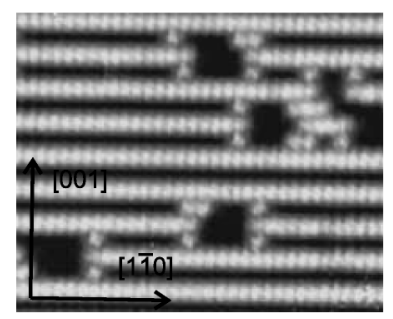

(b)
FIG. 1. (a) Model of the missing-row Pt(110)- $(1 \times 2)$ reconstructed surface. Pt coordination numbers for the perfect surface as well as for various defects are also shown. (b) STM image showing both the clean $\operatorname{Pt}(110)$ structure and the first steps in the transformation observed upon $\mathrm{CO}$ exposure at RT. 

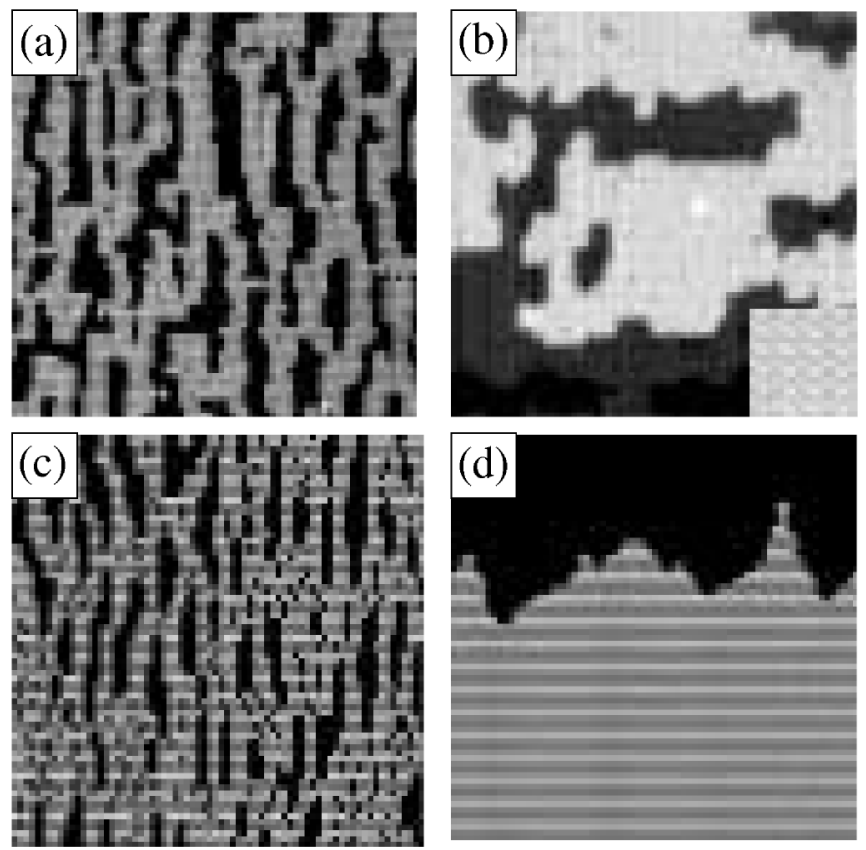

FIG. 2. STM images of $\operatorname{Pt}(110)$ at a CO coverage of $(\mathrm{a}) \simeq 0.8$ and (b) 1 , the latter imaged in a $10^{-7}$ Torr $\mathrm{CO}$ background. The inset shows individual $\mathrm{CO}$ molecules in the $(2 \times 1)$ structure. The images are taken at $300 \mathrm{~K}$ as explained in the text. (c),(d) Snapshots from a Monte Carlo simulation of the surface structure at $300 \mathrm{~K}$ and at the same two coverages. All parameters are deduced from DFT calculations.

$\left(\theta_{\mathrm{CO}}=0.8\right)$ in which case there is a large number of steps - in fact $52 \%$ of the Pt surface atoms have fewer than seven Pt nearest neighbors; or, equivalently, $52 \%$ of the surface atoms are associated with steps in the close-packed direction. There is also a tendency for an attractive nextnearest-neighbor (NNN) interaction indicated by alignment of Pt islands perpendicular to the close-packed rows.

In the following we focus primarily on the rough surface structure at intermediate $\mathrm{CO}$ coverages. We will show that it indeed represents an equlibrium structure of the system, where adsorption has lowered the step formation energy to a value close to zero. Steps and other defects on the surface are characterized by Pt atoms with a low Pt coordination number, cf. Fig. 3a. We have studied the adsorption energy of $\mathrm{CO}$ on $\mathrm{Pt}(110)$, as a function of the Pt coordination number, using density functional theory (DFT) [9-11]. The calculations are performed with electronic exchange and correlation described within the generalized gradient approximation (PW91) [12]. The surface is modeled by slabs of nine $\mathrm{Pt}(110)$ layers, where the top three layers and the $\mathrm{CO}$ coordinates are fully relaxed. The numerical setup is identical to the one described in Ref. [13].

Figure 3a shows that $\mathrm{CO}$ molecules bond strongly to $\mathrm{Pt}$ atoms with a low $\mathrm{Pt}$ coordination number, while $\mathrm{Pt}$ atoms with a high coordination number bind $\mathrm{CO}$ more weakly. On the unperturbed $\mathrm{Pt}(110)-(1 \times 2)$ surface, $\mathrm{CO}$ prefers to bond to $\mathrm{Pt}$ atoms at ridges, since these $\mathrm{Pt}$ atoms have
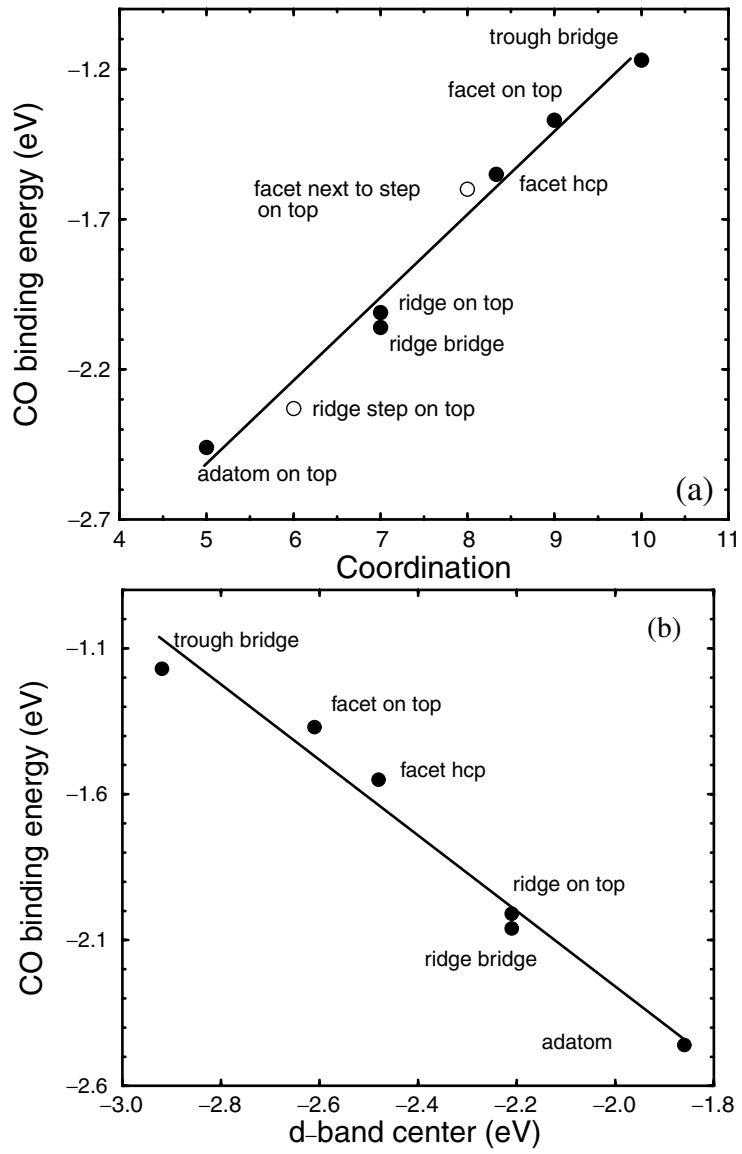

FIG. 3. (a) Calculated $\mathrm{CO}$ chemisorption energies at different positions on the $\operatorname{Pt}(110)$ surface versus the mean coordination number of the nearest platinum atoms. With the open symbols we include data for $\mathrm{CO}$ adsorption on a $\mathrm{Pt}$ dimer on $\mathrm{Pt}(110)$ (coordination number 6) from Feibelman [25], and on a $\mathrm{Pt}(100)$ surface (coordination number 8) from Hammer et al. [16]; see Table I for details. (b) Data for Pt(110) plotted as a function of the average energy of the $d$ states to which the CO interacts. As the metal coordination number is reduced the local $d$ band moves up and narrows leading to stronger bonding.

a coordination number of 7 in contrast to the $\mathrm{Pt}$ atoms on the sides of the troughs with a coordination number of 9. A Pt atom at a step perpendicular to the close-packed direction or a single Pt atom in the troughs have coordination numbers 6 and 5, respectively (see Fig. 1), and they therefore bind $\mathrm{CO}$ even stronger than $\mathrm{Pt}$ atoms at the ridges. The important point in the present context is that the extra bonding of $\mathrm{CO}$ to the low coordinated $\mathrm{Pt}$ atoms is of the same order of magnitude as the energy required to form the defect with a low coordinated Pt atom. The difference in adsorption energy on, e.g., an adatom (coordination number 5) and on the ridge (coordination number 7) is found to be $0.45 \mathrm{eV}$. This should be compared to the energy of forming an adatom, which we calculate to be essentially the same, $0.45 \mathrm{eV}$. The accuracy of the DFT calculations allows us to say only that the effective defect formation energy in the presence of $\mathrm{CO}$ becomes 
close to zero. Nonetheless, we note that even a slightly positive step formation energy will lead to a surface with many steps at finite temperatures due to the higher entropy of the defected surface. Based on the DFT calculations it therefore seems very likely that $\mathrm{CO}$ adsorption should be able to break up the $\operatorname{Pt}(110)-(1 \times 2)$ surface completely at RT, as is indeed observed experimentally.

To further substantiate that the experimentally observed rough structure at $\theta_{\mathrm{CO}}<1$ is indeed the equilibrium structure, we compare it in more detail to the structure expected from DFT calculations. We have performed Monte Carlo (MC) simulations of the equilibrium structure corresponding to the energetics of the DFT calculations. In the simulations the total energy of the system is written as

$$
E=\frac{1}{2} \sum_{i, j} V_{i j}
$$

where $i$ and $j$ run over all $\mathrm{Pt}$ atoms in the first two layers and over the $\mathrm{CO}$ molecules. $\mathrm{CO}$ can adsorb on all $\mathrm{Pt}$ atoms in the two outermost layers. All interaction energies are deduced from DFT calculations, as shown in Table I [14]. We simulate $100 \times 100$ surface unit cells starting from the perfect missing row $(1 \times 2)$ reconstructed surface. We then adsorb $\mathrm{CO}$ molecules to a specific coverage and equilibrate at $300 \mathrm{~K}$ by running $10^{4}$ trial moves per site. Snapshots at two coverages are shown below the corresponding STM pictures in Fig. 2. Clearly a good qualitative agreement is found.

From the simulations we calculate the equilibrium number of defects/steps as a function of CO coverage, Fig. 4a [15]. The number of steps shows a maximum around a $\mathrm{CO}$ coverage of 0.7 . Here the number of steps is as high as $90 \%$. We have not investigated this extreme coverage experimentally but at a coverage of 0.8 the MC simulation shows about $60 \%$ steps, in good agreement with the experimental value. At a more detailed level, we can compare the experimental and theoretical values for the frequency

TABLE I. Parameters used in MC simulations. NN: nearest neighbors. NNN: next-nearest neighbors. $a$ : This work. $b$ : The energy difference $\mathrm{V}_{\mathrm{CO} / \mathrm{Pt}}($ coord. $=6)-\mathrm{V}_{\mathrm{CO} / \mathrm{Pt}}($ coord. $=5)=$ $E_{\text {dis }}$ ("empty" dimer)- $E_{\text {dis }}$ (dimer with $1 \mathrm{CO}$ on top) is estimated from calculations by Feibelman [25]. $c$ : The energy difference $\mathrm{V}_{\mathrm{CO} / \mathrm{Pt}}($ coord. $=7)-\mathrm{V}_{\mathrm{CO} / \mathrm{Pt}}($ coord. $=8,9)$ is estimated from calculations on $\operatorname{Pt}(1185)$ [16]. $d$ : Estimated from calculations by Feibelman [25]. $e$ : Estimated from calculations on $\mathrm{Au}(110)$ [23].

\begin{tabular}{lcc}
\hline \hline \multicolumn{1}{c}{ Parameter } & Value $(\mathrm{eV})$ & Remarks \\
\hline $\mathrm{V}_{\mathrm{CO} / \mathrm{Pt}}($ coord. $=5)$ & -2.46 & $a$ \\
$\mathrm{~V}_{\mathrm{CO} / \mathrm{Pt}}$ (coord. $\left.=6\right)$ & -2.33 & $b$ \\
$\mathrm{~V}_{\mathrm{CO} / \mathrm{Pt}}$ (coord. $\left.=7\right)$ & -2.01 & $a$ \\
$\mathrm{~V}_{\mathrm{CO} / \mathrm{Pt}}$ (coord. $\left.=8\right)$ & -1.60 & $c$ \\
$\mathrm{~V}_{\mathrm{CO} / \mathrm{Pt}}$ (coord. $\left.=9\right)$ & -1.37 & $c$ \\
$\mathrm{~V}_{\mathrm{Pt}, \mathrm{Pt}}(\mathrm{NN})$ & -0.45 & $a$ \\
$\mathrm{~V}_{\mathrm{CO}, \mathrm{CO}}(\mathrm{NN})$ & 0.06 & $d$ \\
$\mathrm{~V}_{\mathrm{Pt}, \mathrm{Pt}}(\mathrm{NNN})$ & 0.10 & $e$ \\
\hline \hline
\end{tabular}

of Pt rows of different lengths at the coverage 0.8, Fig. 4b. The experimental results show a most probable chain length of three while the MC simulations find this number to be two, but given the fact that no fitting of the parameters has been made and the fact that the experimental determination of the $\mathrm{CO}$ coverage is somewhat uncertain, the agreement is quite satisfactory. We therefore suggest that the rough surface observed at a CO coverage at about 0.8 is a direct observation of adsorption-induced roughening.

From the discussion above it is clear why the number of step atoms increases with the CO coverage. Since CO adsorption strongly stabilizes Pt step atoms, they increase in number proportional to the $\mathrm{CO}$ coverage. The reason for the decrease in the number of step atoms at the highest coverages is equally simple: As the CO coverage approaches 1 , every Pt surface atom, including those below
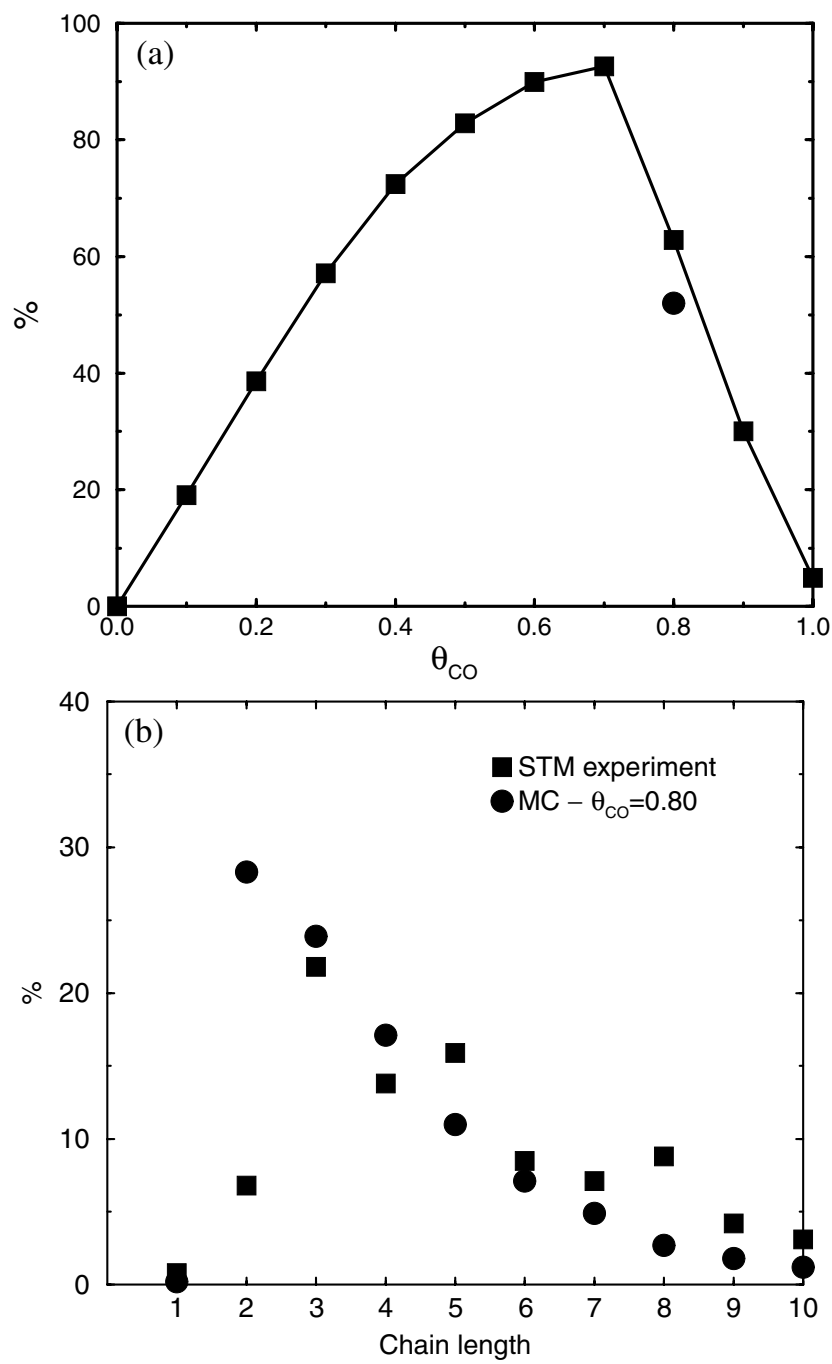

FIG. 4. (a) Step density calculated at $300 \mathrm{~K}$ based on the DFT parameters of Table I shown as a function of the $\mathrm{CO}$ coverage. The experimental observation at a coverage of 0.8 is included as a circle. (b) A comparison of measured and calculated probabilities of finding $\mathrm{Pt}$ rows of different lengths. 
steps, must have an adsorbed $\mathrm{CO}$. These Pt atoms have a coordination number higher than 7 , and they therefore have a lower $\mathrm{CO}$ adsorption energy than the first layer of surface atoms. The energy gain associated with step formation disappears because the energy gain from $\mathrm{CO}$ adsorption on top of the step is cancelled by the energy loss due to $\mathrm{CO}$ adsorption at the bottom of the step. As the $\mathrm{CO}$ coverage approaches 1 the surface therefore heals again. This need not be the case if $\mathrm{Pt}$ atoms from deeper layers could migrate and form new steps. We suggest that at the high $\mathrm{CO}$ coverages of the experiment this process may be too activated to take place at the moderate temperatures reached. If, on the other hand, the CO coverage could be maintained at higher temperatures, it is possible that the surface would roughen completely.

The lineup of Pt islands in the direction perpendicular to the close-packed rows is also related to the relative proportion of coordination number 6 and 8 adsorption sites. By lining up, the number of coordination number 8 adsorption sites is minimized.

Adsorption-induced microroughening is not limited to the $\mathrm{CO} / \mathrm{Pt}(110)$ system. Any adsorbate which is attracted to a step atom by an energy comparable to the step formation energy should induce disordering on any facet. $\mathrm{CO}$ also binds strongly to steps of other Pt surfaces [16], and the same has been established for $\mathrm{NO}, \mathrm{O}, \mathrm{N}$, and $\mathrm{C}$ on a number of different transition metals [17-19]. The underlying reason is that the step atoms with a low coordination number have high energy $d$ electrons, which interact more strongly with adsorbate states [20,21]. This is illustrated in Fig. $3 \mathrm{~b}$ for $\mathrm{CO} / \mathrm{Pt}(110)$. It should be stressed, though, that the strength of the effect is system specific [19].

The effect is particularly strong at fcc(110) surfaces because the metal atoms along steps perpendicular to the close-packed rows are so far apart that each of them can accommodate an adsorbate without strong adsorbateadsorbate interactions. The coverage can become large at high gas pressures, and adsorption-induced step formation may be possible in general. One report of high pressure, CO-induced roughening of $\mathrm{Pt}(110)$ exists [22], but such experiments are presently very rare. Our suggestion is that for a number of gas/metal systems high pressures of gases will induce substantial changes in the morphology of the surface at high temperatures. One immediate consequence is that we must expect that, e.g., catalysts can change morphology as a function of gas composition and pressure, and that the distribution of active sites, and thus the catalytic activity, is self-regulated by gas adsorption.

We acknowledge financial support from the Danish National Research Foundation through the Center for AtomicScale Materials Physics (CAMP).
*Corresponding author.

Email address: fbe@ifa.au.dk

[1] E. H. Conrad and T. Engel, Surf. Sci. 299/300, 391 (1994).

[2] P. Fery, W. Moritz, and D. Wolf, Phys. Rev. B 38, 7275 (1988).

[3] P. Thostrup, S. Helveg, E. Lægsgaard, I. Stensgaard, and F. Besenbacher (to be published).

[4] One monolayer is defined as one monolayer on $\operatorname{Pt}(110)$ $(1 \times 1)$, and one monolayer equals the atomic density of $\operatorname{Pt}(110)-(1 \times 1)$.

[5] T. Gritsch, D. Coulman, R. J. Behm, and G. Ertl, Phys. Rev. Lett. 63, 1086 (1989).

[6] P. Hofmann, S. R. Bare, and D. A. King, Surf. Sci. 117, 245 (1982).

[7] S. R. Bare, P. Hofmann, and D. A. King, Surf. Sci. 144, 347 (1984).

[8] R. K. Sharma, W. A. Brown, and D. A. King, Surf. Sci. 414, 68 (1998).

[9] P. Hohenberg and W. Kohn, Phys. Rev. 136, B864 (1964).

[10] B. Hammer, L. B. Hansen, and J. K. Nørskov, Phys. Rev. B 59, 7413 (1999).

[11] P. J. Feibelman, B. Hammer, and J. K. Nørskov, F. Wagner, M. Scheffler, R. Stumpf, R. Watwe, and J. Dumesic (to be published).

[12] J. P. Perdew et al., Phys. Rev. B 46, 6671 (1992).

[13] H. T. Lorensen and J. K. Nørskov, and K. W. Jacobsen, Phys. Rev. B 60, R5149 (1999).

[14] The reconstruction energy of the clean Pt(110) surface needed to obtain the NNN interactions between Pt has not been calculated. Instead, it was estimated from calculations on $\mathrm{Au}(110)$ [23] by scaling the reconstruction energy of $\mathrm{Au}(110)$ with the surface energies of $\mathrm{Pt}(110)$ and $\mathrm{Au}(110)$ [24]. This number turned out to be important only for simulated structures found at $\theta_{\mathrm{CO}} \lesssim 0.2$.

[15] A step is defined as a Pt atom with a coordination number lower than 7.

[16] B. Hammer, O. H. Nielsen, and J. K. Nørskov, Catal. Lett. 46, 31 (1997).

[17] M. Mavrikakis, P. Stoltze, and J. K. Nørskov, Catal. Lett. 64, 101 (2000).

[18] B. Hammer and J. K. Nørskov, Phys. Rev. Lett. 79, 4441 (1997).

[19] B. Hammer, J. Catal. 199, 171 (2001).

[20] B. Hammer, Y. Morikawa, and J. K. Nørskov, Phys. Rev. Lett. 76, 2141 (1996).

[21] B. Hammer and J. K. Nørskov, in Theory of Adsorption and Surface Reactions, edited by R. Lambert and G. Pacchioni NATO ASI Ser. E, Vol. 331 (Kluwer, Dordrecht, 1997).

[22] B. J. McIntyre, M. Salmeron, and G. Somorjai, J. Vac. Sci. Technol. A 11, 1964 (1992).

[23] K.-M. Ho and K. P. Bohnen, Phys. Rev. Lett. 59, 1833 (1987).

[24] L. Vitos, A. V. Ruban, H. L. Skriver, and J. Kollar, Surf. Sci. 411, 186 (1998).

[25] P. J. Feibelman, Phys. Rev. B 61, R2452 (2000). 